\title{
The Socio-cultural Behaviours of Women's Health Facilities Utilisation in Northern Nigeria
}

\author{
Muazu Alhaji Shamaki \\ Department of Geography, Faculty of Social Sciences, Usmanu Danfodiyo University, Sokoto-Nigeria \\ Email:mashamakisa@yahoo.com \\ Prof. Dr. Amriah Buang \\ School of Social, Development and Environment Studies, \\ Faculty of Social Sciences and Humanities, Universiti Kebangsaan Malaysia \\ Email:amriah@ukm.edu.my
}

\section{Doi:10.5901/mjss.2015.v6n4s3p517}

\section{Abstract}

This study looks at the influence of socio-cultural behaviours and women's health facilities utilisations in northern Nigeria. A Pearson's correlation statistical analysis was employed using a questionnaire administered to 315 women between the ages of 15 and 45 years. The findings indicate husband's permission had strong significant relationships to antenatal care services (ANC). In addition, there were strong significant relationships between women limited freedom and female genital mutilation in terms of skilled delivery (DC) as well as husband's permission and limited freedom of women among others. Also, a strong significant relationship exists between the postnatal care services (PNC) and limited women freedom as well as with home delivery and hot-bathing practices among others. To improve women health care utilisation and maternal health in northern Nigeria, this study provides useful planning information drawn from the women sociocultural behaviours leading to the consequent low modern health facilities utilisations.

Keywords: health facilities; socio-cultural behaviours; women's health; facilities utilisation, northern-Nigeria.

\section{Introduction}

Sociocultural and demographic factor is one of the important groups of variables that influence women's access and utilisation of modern health facilities world over. The cultural factors are seen in the value system of the people, their tradition, custom, religion, education and food grown and eaten, materials, taboos and beliefs ( Peplau et al. 1997, Otalike 2009 \& Idowu 2013). It is a way of life of people, a sum of values transmitted overtime among community members. However, in this study, sociocultural status (SCS) covers social, cultural, economic and sociological combined total measure of an individual's or family's background as well as the social position based on cultural, income, education and occupation. High illiteracy and socio-cultural behaviours contribute to the low accessibility of health facilities in Nigeria (Idowu, 2013). In a related development, Chukuezi (2010) undertakes a study on sociocultural factors associated with maternal mortality and noted that Nigeria is by tradition a patriarchal society where women are discriminated against from infancy. He explained in terms of facilities utilisation, poorer access to the medical services is compounded by social, cultural and economic factors including gender inequality, access to food, by burden of work and by special dietary requirements such as iron supplements among women.

Similarly, being a patriarchal society, Nigeria reflects a lot of cultural norms and beliefs which are discriminatory and bias against the physical and social well-being of women because most traditional cultural practices and beliefs are more beneficial to the men (Abdul et al., 2012 \& Peplau et al., 1997). Therefore, gender inequality continues to be linked to various traditional practices of many cultural groups of varying geographical locations and many cultures promote the belief that in Nigeria women do not have an identity of their own but those derive from men. Gender inequalities are defined and perpetuated by social norms and culture and reflects differences in power between men and women both within the household and in the wider society (Doctor et al. 2011, Idowu 2013 \& Pathfinder International 2013). Various studies indicate deeply entrenched gender inequalities exist on many low-income regions where maternal deaths are high and health service utilization is low (Pathfinder International, 2013). The effects of this include relatively higher rates of poverty and lower levels of education among women than men as well as women's lack of autonomy and mobility, 
intimate partner violence and overall lower social status and disempowerment of women relative to men (Pathfinder International, 2013).

Therefore, in this study, the sociocultural behaviours and practices which appear to be the most influential in lowering of the health care utilisation by women in Nigeria have been examined using Pearson's correlation approach. Variables that include limited freedom of woman, husband's approval to go for services or husband's permission, home delivery practice, hot-bath practice and female genital mutilation were all used for the study. This is in line with Roost (2010) who asserts that lowest and middle-income countries show high maternal mortality figures and low utilization of maternal health care among women with low education, low economic status, and place of rural residence. This study aims to examine the relationship between sociocultural behaviours, practices as well as the pattern of health facilities utilisation in Nigeria. The main goal is to find out how different sociocultural behaviours and practices among women with northern Nigeria backgrounds relate to the specific type of health care facility utilisation that could consequently influences the rate of maternal mortality in the study area due to nonchalant attitude towards utilisation and general health seeking behaviour. Hence, it will therefore try to identify levels of the underlying sociocultural factors affecting the utilisation of maternal health facilities and suggest ways of improving the maternal health and reduce maternal mortality.

\section{Literature Review}

In reviewing studies on maternal health service utilization, Thaddeus and Maine observed that many pregnant women reach health facilities in such a poor condition that they cannot be saved (Pacagnella et al., 2012). At the same time, Gazali (2012) indicates that most women underutilize maternal health care services due to poverty, illiteracy, general backwardness and adherence to superstitious belief concerning illness and diseases. Therefore, common practices like early marriage and pregnancy, polygyny, large family size, childbirth beliefs and practices, purdah, low self-esteem among women, traditional medicine, and religion and rituals during labour are all cultural factors inhibiting utilisation of services in Nigeria (Gazali, 2012). While on the other hand, Chukuezi (2010) affirms that in terms of facilities utilisation, poorer access to the medical services is compounded by social, cultural and economic factors including gender inequality. As such therefore, Azuh (2012) defined maternal or women's health as means for ensuring that all women receive the care they need to be safe and healthy throughout pregnancy and childbirth. He asserts that women's health is a critical area and reflects national health standards and basic to women's advancement. In another development, records have shown that the access to maternal services is not very encouraging in Sokoto especially when compares with the population of the state. The situation as reported in the NDHS (2008) shows that 95.3percent of women of reproductive age (15-49 years) who delivered within the five years of the survey had home delivery and only 4.4 percent in a health facility. Also only 2.0 percent had intermittent preventive treatment (IPT) during pregnancy, 13.0 percent had iron supplements in the previous pregnancy, and 0.3 percent had anti-helminths.

However, only 18.0 percent of the pregnant women who attended ANC had information on the danger signs of pregnancy and 6.8percent had two doses of tetanus toxoid (TT) in their last pregnancy (NDHS, 2008 \& TSHIP, 2010). Furthermore, 60.0 percent of women (15-49 years) had one or more challenges accessing health care which included lack of money to pay for services, non-availability of provider at the facility and where a male provider is available there is reluctance to visit such provider, in addition to the perennial lack of essential drugs in the facilities (NDHS, 2008 \& TSHIP, 2010). This situation compels the use of inappropriate treatments of diseases during pregnancy rather than evidencebased approaches by women compounded by traditional practices such as early marriage and high level of poverty in the country among pregnant woman in Nigeria are other social factors that contribute to poor health (UNFPA, 2004 \& Galadanci et'al., 2010). Generally, in Nigeria the NDHS (2013) provides maternal health indicators among women aged 15-49 who had live-birth in the last five years shows that Sokoto state is the least in Nigeria with 5.4 and 4.7 percent in terms of percent of delivery by a skilled health provider and percent of those delivered at the hospital respectively. This low percent of utilisation of modern health facilities not only accounts for high ratios in maternal mortality of the area but also the general deaths in the region.

\section{Research Methods}

The demographic information reveals that 88.9 per cent of women in Sokoto state were married while 3.2 per cent and 7.9 per cent were divorced and widowed respectively. The relationship between married women and their husbands are also significant determinant and can enhance access and utilisation of facilities. In terms of level of education, 35.6 percent of the women have no any form of education and only 6.3 per cent attended tertiary educational institutions holding certificates ranging from diploma to graduate levels. Others are within primary, secondary and Arabic education. 
This study was based on Nigeria's northern state of Sokoto due its historical and cultural settings that serves as focal point in the country. Sokoto state, found in the north-western part of Nigeria, is one of the 36 States that make up the Federal Republic of Nigeria. See Figure 1 study area. It was created in after the bifurcation of Zamfara state in 1996. It is a very significant state of Nigeria which other than the economic roles it hold vital religious role of being the seat of caliphate with the Sultan of Sokoto as the Islamic spiritual leader and chairman supreme council of Islamic affairs in Nigeria. However, this study uses primary data obtained from using questionnaires administered to 315 married women aged cohort 15-45 years in the study area as indicated by Flick (2009). A Pearson's correlation was conducted using SPSS version 22 package. It is a correlation between sets of data which is a measure of how well the variables are related (Chandler, 2013). According to Chandler (2013) and Flick (2009), the most common measure of correlations between stats and SPSS is the Pearson Correlation. In this regards, this method shows the relationship between sociocultural behaviours and practices used as variables for this study. Pearson's correlation coefficient when applied to a sample is commonly represented by the letter $r$ and may be referred to as the sample correlation coefficient or the sample Pearson correlation coefficient (Chandler, 2013).

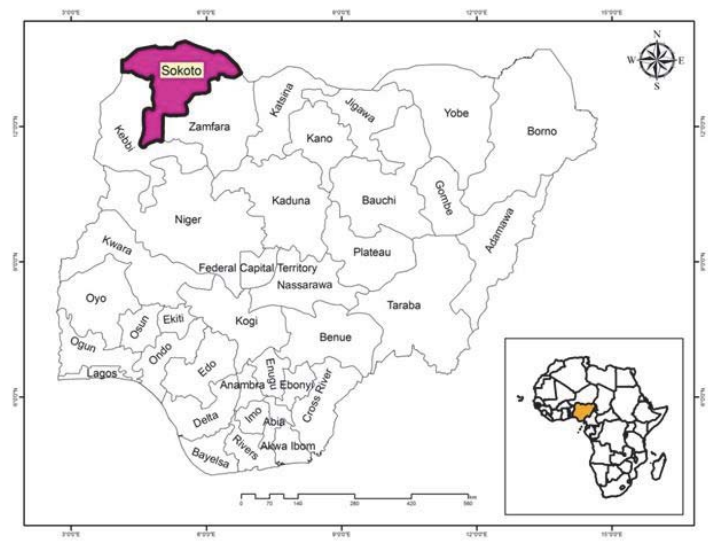

Figure 1: The study area

\section{Analysis Results}

\subsection{Sociocultural factors and ANC}

Table 1. Sociocultural factors and antenatal care service (ANC) utilisation

\begin{tabular}{|c|c|c|c|c|c|c|c|}
\hline & & $\begin{array}{c}\text { Antenatal } \\
\text { care services }\end{array}$ & $\begin{array}{l}\text { Limited freedom of } \\
\text { women }\end{array}$ & $\begin{array}{c}\text { Seek for Husbands } \\
\text { Approval }\end{array}$ & $\begin{array}{c}\text { Home } \\
\text { delivery }\end{array}$ & Hot-bath & $\begin{array}{c}\text { Female genital } \\
\text { mutilation }\end{array}$ \\
\hline \multirow[t]{3}{*}{ Antenatal care services } & Pearson Correlation & 1 & .052 & $-.114^{*}$ & -.049 & -.004 & -.013 \\
\hline & Sig. (2-tailed) & & .353 & .043 & .384 & .939 & .824 \\
\hline & $\mathrm{N}$ & 315 & 315 & 315 & 315 & 315 & 315 \\
\hline \multirow[t]{3}{*}{ Limited freedom of women } & Pearson Correlation & .052 & 1 & $-.284^{* *}$ & $.366^{*+}$ & -.063 & $-.214^{* *}$ \\
\hline & Sig. (2-tailed) & .353 & & .000 & .000 & .269 & .000 \\
\hline & N & 315 & 315 & 315 & 315 & 315 & 315 \\
\hline \multirow[t]{3}{*}{ Seek for Husbands Approval } & Pearson Correlation & $-.114^{*}$ & $-.284^{* *}$ & 1 & $-.132^{*}$ & .022 & $.116^{*}$ \\
\hline & Sig. (2-tailed) & .043 & .000 & & .019 & .692 & .040 \\
\hline & $\mathrm{N}$ & 315 & 315 & 315 & 315 & 315 & 315 \\
\hline \multirow[t]{3}{*}{ Home delivery } & Pearson Correlation & -.049 & $.366^{*+}$ & $-.132^{*}$ & 1 & $-.126^{*}$ & $-.139^{*}$ \\
\hline & Sig. (2-tailed) & .384 & .000 & .019 & & .025 & .014 \\
\hline & $\mathrm{N}$ & 315 & 315 & 315 & 315 & 315 & 315 \\
\hline \multirow[t]{3}{*}{ Hot-bath } & Pearson Correlation & -.004 & -.063 & .022 & $-.126^{*}$ & 1 & .006 \\
\hline & Sig. (2-tailed) & .939 & .269 & .692 & .025 & & .917 \\
\hline & $\mathrm{N}$ & 315 & 315 & 315 & 315 & 315 & 315 \\
\hline \multirow[t]{3}{*}{ Female genital mutilation } & Pearson Correlation & -.013 & $-.214^{* \star}$ & $.116^{*}$ & $-.139^{*}$ & .006 & 1 \\
\hline & Sig. (2-tailed) & .824 & .000 & . 040 & .014 & 917 & \\
\hline & $\mathrm{N}$ & 315 & 315 & 315 & 315 & 315 & 315 \\
\hline
\end{tabular}


Table 1 shows the statistical analysis performed to examine the relationship between sociocultural factors and antenatal health care facility utilisations. The findings indicate significant relationships between ANC services and other variables included. In fact, one of the strongest factors is the mandatory husband approval (permission) of his wife to obtain services where the result shows significant relationship $(r=-0.114, p$. value $<0.043)$ between ANC and husband's approval, correlation significant at the 0.05 level (2-tailed), meaning most women cannot access facilities because of lack of husband's permission. This finding is in line with Bakare (2011) who found that a woman's decision to seek health care is shaped by several factors, including the influence of her spouse (husband) or other family members, social norms, her education and her status in society. Also, the bivariate correlation showing association between woman's limited freedom and husband's approval indicates a strong association $(r=-0.284$; $p$. value $<0.000)$, significant at the 0.01 level (2tailed), explaining that freedom of women is guided by their husband. Similarly, for associations with husband approval to obtain maternal health services and home delivery, the Pearson correlation is strongly significant $(r=-0.132$; $p$. value < .019 at 0.05 level (2-tailed), implying a strong linkage leading to high rate of home delivery.

On the other hand, the correlations between female genital mutilation and husband approval is strongly significant $(r=0.116$, p-value $<0.040)$, correlation significant at the 0.05 level (2-tailed) and this coincides with Okhiai et al. (2011) and Ajiboye et al. (2012) who assert that female genital mutilation does irreparable harm and it can result in maternal death through severe bleeding leading to haemorrhagic shock, neurogenic shock as a result of pain and trauma, and severe overwhelming infection and septicaemia, hence, it is routinely traumatic. Further findings reveal that home delivery and limited women freedom have strong association with $r$ value $0.366, p$. value $<0.000$ significant at the 0.01 (2-tailed). Similarly, measuring associations with hot-bath and home delivery practices indicate strong relationship $(r=0.126 ; p$. value $<0.025)$ significant at 0.05 (2-tailed). This establishes the fact that most women deliver at home undertakes hotbathing in the study area. Again, the result shows there is relationship between hot-bath and female genital mutilation $(r=$ -0.139 ; $p$. value < 0.014) significant at 0.05 levels while for female genital mutilation and limited freedom there is a strong relationship $(r=-0.214$, p. value $<0.000)$ correlations significant at the 0.01 level $(2$-tailed).

\subsection{Sociocultural factors and DC}

Table 2. Sociocultural factors and delivery care services (DC) utilisation

\begin{tabular}{|c|c|c|c|c|c|c|c|}
\hline & & $\begin{array}{c}\text { Delivery care } \\
\text { services }\end{array}$ & $\begin{array}{l}\text { imited freedom } \\
\text { of women }\end{array}$ & $\begin{array}{c}\text { Seek for Husbands } \\
\text { Approval }\end{array}$ & $\begin{array}{c}\text { Home } \\
\text { delivery }\end{array}$ & $\begin{array}{l}\text { Hot- } \\
\text { bath }\end{array}$ & $\begin{array}{c}\text { Female genital } \\
\text { mutilation }\end{array}$ \\
\hline \multirow[t]{3}{*}{ Delivery care services } & Pearson Correlation & 1 & .061 & .042 & .036 & -.060 & .019 \\
\hline & Sig. (2-tailed) & & .280 & .460 & .527 & .290 & .742 \\
\hline & $\mathrm{N}$ & 315 & 315 & 315 & 315 & 315 & 315 \\
\hline \multirow[t]{3}{*}{ Limited freedom of women } & Pearson Correlation & .061 & 1 & $-.284^{\star *}$ & $.366^{* *}$ & -.063 & $-.214^{\star *}$ \\
\hline & Sig. (2-tailed) & .280 & & .000 & .000 & .269 & .000 \\
\hline & $\mathrm{N}$ & 315 & 315 & 315 & 315 & 315 & 315 \\
\hline \multirow[t]{3}{*}{ Seek for Husbands Approval to facility } & Pearson Correlation & .042 & $-.284^{\star \star}$ & 1 & $-.132^{\star}$ & .022 & $.116^{\star}$ \\
\hline & Sig. (2-tailed) & .460 & .000 & & .019 & .692 & .040 \\
\hline & $\mathrm{N}$ & 315 & 315 & 315 & 315 & 315 & 315 \\
\hline \multirow[t]{3}{*}{ Home delivery } & Pearson Correlation & .036 & $.366^{* \star}$ & $-.132^{\star}$ & 1 & $-.126^{*}$ & $-.139^{*}$ \\
\hline & Sig. (2-tailed) & .527 & .000 & .019 & & .025 & .014 \\
\hline & $\mathrm{N}$ & 315 & 315 & 315 & 315 & 315 & 315 \\
\hline \multirow[t]{3}{*}{ Hot-bath } & Pearson Correlation & -.060 & -.063 & .022 & $-.126^{\star}$ & 1 & .006 \\
\hline & Sig. (2-tailed) & .290 & .269 & .692 & .025 & & .917 \\
\hline & $\mathrm{N}$ & 315 & 315 & 315 & 315 & 315 & 315 \\
\hline \multirow[t]{3}{*}{ Female genital mutilation } & Pearson Correlation & .019 & $-.214^{* *}$ & $.116^{*}$ & $-.139^{\star}$ & .006 & 1 \\
\hline & Sig. (2-tailed) & .742 & .000 & .040 & .014 & .917 & \\
\hline & $\mathrm{N}$ & 315 & 315 & 315 & 315 & 315 & 315 \\
\hline
\end{tabular}

Table 2 presents the outcome of the bivariate correlation conducted to find associations between sociocultural behaviours/practices and utilisation of facilities for delivery care services in Sokoto state. The results revealed that Pearson's $r$ correlation statistical analysis show strong significant relationships between women limited freedom and female genital mutilation $(r=-0.214$, p. value $<0.000$ ); similarly, husbands approval (permission) and limited freedom of women $(r=-0.284$, p. value $<0.000)$ and between home delivery and limited freedom of women $(r=0.366$, p. value $<0$ .000 ) all of which has a correlation significant at the 0.00 levels (2-tailed). In fact, one of the strong factors revealed is the mandatory approval of a husband for his wife to obtain services in which the result shows significant relationship $(r=$ $0.114, p<0.043)$ between the services and husband's approval, correlation significant at the 0.05 level (2-tailed). This 
means a woman cannot seek health care at the facility without the permission of her husband irrespective of the level of her illness.

Further analysis on measuring of the association for sociocultural factors indicates significant relationship $(r=$ 0.132 , p. value $<0.019$ ) between home delivery and husband's approval and permission to deliver at health facility, with correlation significant at the 0.05 (2-tailed). This has proven that most women could not deliver to the facility because of their husband's refusal. Similarly, the Pearson's $r$ correlation is strongly significant $(r=0.116, p$. value $<0.040)$ between husband's approval and female genital mutilation, with correlation significant at 0.05 level (2-tailed). Whereas, associations with hot-bath and home delivery is also strongly significant at $r=-0.126$ and $p$. value of 0.025 at the 0.05 levels (2-tailed) so, also the Pearson's $r$ correlation further shows strong significant relationship $(r=-0.139$, p. value < 0.014 ) with correlations significant at the 0.05 level (2-tailed) between home delivery and female genital mutilation in Sokoto state.

\subsection{Sociocultural factors and PNC}

Table 3. Sociocultural factors and postnatal care service (PNC) utilisation

\begin{tabular}{|c|c|c|c|c|c|c|c|}
\hline & & $\begin{array}{l}\text { Postnatal care } \\
\text { services }\end{array}$ & $\begin{array}{l}\text { Limited } \\
\text { freedom of } \\
\text { women }\end{array}$ & $\begin{array}{c}\text { Seek for } \\
\text { Husbands } \\
\text { Approval }\end{array}$ & $\begin{array}{l}\text { Home } \\
\text { delivery }\end{array}$ & $\begin{array}{l}\text { Hot- } \\
\text { bath }\end{array}$ & $\begin{array}{c}\text { Female genital } \\
\text { mutilation }\end{array}$ \\
\hline \multirow[t]{3}{*}{ Postnatal care services } & Pearson Correlation & 1 & $-.134^{\star}$ & .084 & $-.145^{\star \star}$ & $-.122^{*}$ & .001 \\
\hline & Sig. (2-tailed) & & .018 & .137 & .010 & .030 & .980 \\
\hline & $\mathrm{N}$ & 315 & 315 & 315 & 315 & 315 & 315 \\
\hline \multirow[t]{3}{*}{ Limited freedom of women } & Pearson Correlation & $-.134^{*}$ & 1 & $-.284^{\star \star}$ & $.366^{* *}$ & -.063 & $-.214^{* \star}$ \\
\hline & Sig. (2-tailed) & .018 & & .000 & .000 & .269 & .000 \\
\hline & $\mathrm{N}$ & 315 & 315 & 315 & 315 & 315 & 315 \\
\hline \multirow[t]{3}{*}{ Seek for Husbands Approval } & Pearson Correlation & .084 & $-.284^{*+}$ & 1 & $-.132^{*}$ & .022 & $.116^{*}$ \\
\hline & Sig. (2-tailed) & 137 & .000 & & 019 & .692 & .040 \\
\hline & $\mathrm{N}$ & 315 & 315 & 315 & 315 & 315 & 315 \\
\hline \multirow[t]{3}{*}{ Home delivery } & Pearson Correlation & $-.145^{* *}$ & $.366^{*+}$ & $-.132^{*}$ & 1 & $-.126^{*}$ & $-.139^{*}$ \\
\hline & Sig. (2-tailed) & .010 & .000 & 019 & & .025 & .014 \\
\hline & $\mathrm{N}$ & 315 & 315 & 315 & 315 & 315 & 315 \\
\hline \multirow[t]{3}{*}{ Hot-bath } & Pearson Correlation & $-.122^{*}$ & -.063 & .022 & $-.126^{*}$ & 1 & .006 \\
\hline & Sig. (2-tailed) & .030 & .269 & 692 & .025 & & 917 \\
\hline & $\mathrm{N}$ & 315 & 315 & 315 & 315 & 315 & 315 \\
\hline \multirow[t]{3}{*}{ Female genital mutilation } & Pearson Correlation & .001 & $-.214^{* *}$ & $.116^{*}$ & $-.139^{\star}$ & .006 & 1 \\
\hline & Sig. (2-tailed) & .980 & .000 & .040 & .014 & .917 & \\
\hline & $\mathrm{N}$ & 315 & 315 & 315 & 315 & 315 & 315 \\
\hline
\end{tabular}

Table 3 shows the bivariate correlation performed to measure associations with sociocultural factors and postnatal care services at health facility in the study area. The result at the end of the Pearson's $r$ correlation indicates strong significant relationships $(r=-0.134$, p. value $<0.018$ correlations significant at 0.05 levels between postnatal care services and limited women freedom, strong significant relationship $r=-0.145$, $p$. value $<0.010$ correlations significant at the 0.01 level between postnatal care services and home delivery and also strong significant relationship $r=-0.122$, p. value $<0.030$ correlations significant at 0.05 level) (2-tailed) between postnatal care services ant hot-bath. Another important relationships examined in this correlations revealed a strong significant relationships $(r=-0.214$, p. value $<0.000$ with correlations significant at the 0.01level 2-tailed) between limited freedom and female genital mutilation and $r=-0.284, p$. value $<0.000$ with correlation significant at the 0.01 level (2tailed) between husband's approval for postnatal care services and limited freedom of women. While, the analysis between home delivery and limited freedom shows a distinguished strong significant relationship $(r=0.366$, p. value $<0.000$, with significant correlation at the 0.01 level 2tailed).

Similarly, the association between home delivery and husband's approval (permission) has strong significant relationship at $r=-0.132, p$. value $<0.019$ with correlations significant at 0.05 levels (2-tailed) even though it is a little more strong significant relationship between variables of home delivery and female genital mutilation at $r=-0.139, p$. value $<0.014$ at 0.05 significant levels. Finally, the correlation examined the relationship between home delivery and hotbath practice in relation to postnatal care services. The analysis shows strong significant relationship $(r=-0.126, p$. value $<0.025$ ) with correlations significant at the 0.05 level 2-tailed. And, finally is the measure of associations between husband's approval and female genital mutilation where the result indicates strong significant relationship $(r=0.116, p$. value $<0.040$ ) with correlations significant at the 0.05 level (2-tailed). 


\section{Discussion of Findings}

The result of the analysis which shows that antenatal care service and husbands permission was significant at the 0.05 level (2-tailed) and by implication in this study, the approval of husband for wife to obtain services in Sokoto state greatly influences the low level of utilisations of maternal health facilities because apart from relationship being significant, the $r$ value is also negative meaning that an increase in the demand for approval from husband leads to a corresponding decrease in level of antenatal care service receive by the woman. Also, the association between husband's approval or permission and home delivery was strongly significant with $p$. value 0.019 at 0.05 significant levels which conforms to Sychareun et al. (2009) that show the lack of privacy and confidentiality was also reported by the women, their mothers and husbands as the reason for giving birth at home. They added that because there were many health staff presents during delivery, the women felt shy and uneasy having to expose themselves to the staff and hence, this is one of the contributing factors for delivery at home.

The relationship between home delivery and limited women freedom was strongly significant $(p$. value $<0.000)$ at 0.01 (2-tailed). This finding is in line with Sychareun et al. (2009) that assert delivering a baby in the right position was also an important factor in choosing to give birth at home. They affirm that some women revealed that when they deliver at home, to be in a sitting position, the women had to hold a rope from the ceiling so that they can be in knee-chest position. While, delivery of the hospital, the women had to lie in the horizontal position on a labour bed with their legs strapped onto the metal stirrups or on the women's back. Moreover, measuring associations with hot-bath, home delivery and female genital mutilation have all shown strong relationships which implies that these factors strongly affect the low level ANC services utilisation that puts women susceptible to frequent maternal mortality in the region.

In terms of delivery care utilisation, the relationship between women limited freedom and female genital mutilation has shown strong significant with $p$. value $<0.000$ as well as between husband's approval and limited freedom of women. This finding is in line with Bakare (2011) and Idowu (2013) who stated that low level of female education especially in northern and rural parts of Nigeria as well as cultural practices inimical to health (male dominance, high rate of home deliveries in some parts like Sokoto state, cultural treatment modalities or use of herbs among others) limit demand and access to health care services. This reaffirms that the low rate of delivery care at the facility in Sokoto state is greatly influenced by sociocultural behaviours and practices of women. Also, there was strong significant relationship ( $p$. value < 0.040 at 0.05 levels) between husband's approval and female genital mutilation while the association was more strongly significant ( $p$. value $<0.025$ at 0.05 levels) between hot-bath and home delivery. And, much more strong significant relationship ( $p$. value $<0.014$ at 0.05 levels) exists between home delivery and the female genital mutilation. This finding conforms to Sychareun et al. (2009) who revealed that female genital mutilation is very inimical to reproductive, social and physical health of women and should be strictly prohibited not only in Nigeria but throughout the world.

Lastly, for the postnatal care services, there were strong significant relationships at $p$. values $<0.018,0.010$ and 0.030 between postnatal care service and limited women freedom, husband's permission and hot-bath in maternity respectively. This result shows that attendance of postnatal care services is determined by the levels of women freedom, preference for home delivery by women and their cultural practices of hot-bath during maternity period leading to high rate of maternal death after delivery in Sokoto state and Nigeria in general. Moreover, the result indicates very strong significant relationship of $p$. value $<0.000$ correlations significant at the 0.01 level 2 tailed between home delivery and limited woman freedom. This implies that women deliver at home because they lack freedom to use health facilities and the more a woman delivers at home, the less the possibility to attend postnatal services at the facility. Therefore, this study holds the view that there is strong synergy that exists between sociocultural behaviours/practices by women and health facilities utilisation in Nigeria. This situation no doubt reduces the rate of utilisation which either directly or indirectly results to high rate of pregnancy complication and subsequent death among women in Nigeria.

\section{Conclusion}

Nigeria being a patriarchal society reflects a lot of cultural norms and beliefs which are sometimes more discriminatory and bias against the well-being of women. Most traditional cultural practices such as hot-bath and female genital mutilation and beliefs are more beneficial to the men. There are strong significant relationships for instance between approval of husband's permission and utilisation of health facility, strong significant relationship between postnatal care services and limited women freedom among other findings. It implies that, based on findings, the strong significant relationship between socio-cultural behaviours and utilisation of health facilities among women in Nigeria brings about the nonchalant attitude of women towards health seeking behaviour leading to low utilisation of facilities and the consequent maternal death among women. To improve the situation, issues like husband's approval, home delivery, hot-bathing and female genital mutilation deserve further investigation in the zone and developing countries at large. 


\section{Acknowledgement}

This paper was based on a field study conducted for the award of the PhD degree to the author titled, Socio-cultural analysis of maternal mortality in Sokoto state. My sincere thanks go to Prof. Dr. Amriah Buang of the School of Social, development and Environment studies, Universiti Kebangsaan Malaysia for supervising the thesis. I also appreciate the co-operation of the Hospital Services Management Board Sokoto and approval of the Sokoto state Ministry of Health to conduct the study area.

\section{References}

Abdul, M. M., Onose, M., Ibrahim, M. T., Voke-Ighorodje, M., Adeyeye, O., Adeleke, O. \& Babalola, A. (2012). An Analysis of the Socio-Economic, Socio-Cultural, Religious, Environmental, Technological, Language and Educational Factors on Women's Right in Nigeria: The Case of Northern Nigeria. Fundación: Mujeres.

Ajiboye, O. E. \& Adeokun, A.K. (2012). Socio-cultural Factors Affecting Pregnancy Outcome among the Ogu Speaking People of Badagry Area of Lagos State, Nigeria. International Journal of Humanities and Social Science, 2(4 [Special Issue - February 2012]): 133-144.

Azuh, D. (2012). Sociodemographic factors influencing health programme usage by pregnant mothers in Nigeria: Implications for policy action, Demography and social statistics program, Covenant University, Ogun sate, Nigeria

Bakare, A. B. F. (2011). Availablity, Accessibility and Utilization of Emergency Obstetric Care Services: A Comparative Study of Two Local Government Areas in Kaduna State, Nigeria. Master of Public Health (MPH) Dissertation, Department of Community Medicine, Faculty of Medicine, Ahmadu Bello University, Zaria, Nigeria.

Chandler, M. (2013). What is SPSS? University of Windsor, Available Online http://www.spss.com (September 4, 2013)

Chukuezi, C. (2010). Socio-cultural factors associated with maternal mortality in Nigeria, Research Journal of Social Sciences, 1(5): 2226,2010

Doctor, H. V., Bairagi, R., Findley, S.E, Helleringer, S. And Dahiru, T. (2011). Northern Nigeria Maternal, Newborn and Child Health Programme: Selected Analyses from Population-Based Baseline Survey. The Open Demography Journal, 4(11-12): 11.

Flick, U. (2009). An Introduction to Qualitative Research. (4th ed.). London: SAGE Publications Ltd

Galadanci, H.I., Idris, S.A., Sadauki, H.M. and Yakasai, I.A. (2010). "Programs and Policies for Reducing Maternal Mortality in Kano State, Nigeria: A Review. African Journal of Reproductive Health, Sept. 2010 (Special Issue) 14 (3): 31

Gazali, W. A., Muktar, F., and Gana, M. M. (2012). Barriers to Utilization of Maternal Health Care Facilities among Pregnant and NonPregnant Women of Child Bearing Age in Maiduguri Metropolitan Council (Mmc) and Jere Lgas of Borno State. Continental J. Tropical Medicine, 6 (1): 12 - 21

Idowu, A. E. (2013). The Socio-Cultural Context of Maternal Health in Lagos State, Nigeria. Ph.D thesis. Department of Sociology, Covenant University, Nigeria

National Population Commission [Nigeria], (2008). Nigeria Demographic and Health Survey, NDHS, 2008. Abuja Nigeria, ICF Macro 2009 Calverton, Maryland, USA

Okhiai, O., Idonije, O.B. \& Asika, E.C. (2011). Awareness of Health Risks of Female Genital Mutilation among Women of Child Bearing Age in Two Rural Communities in Nigeria. Asian Journal of Medical Sciences, 3(6): 223-227.

Otalike, B. N. (2009). Primary Health Care Implementation (Made Easy) in Developing Countries. Enugu-Nigeria: Snaap Press: 20-31.

Pacagnella, R. C., Cecatti, J. G., Osis, M. J. and Souza, J. P. (2012). The Role of Delays in Severe Maternal Morbidity and Mortality: Expanding the Conceptual Framework. Reproductive Health Matters, 20(39): 155-163.

Pathfinder International, (2013). Reproductive health knowledge and practices in northern Nigeria: Challenging misconceptions. The reproductive health/Family planning service delivery project in northern Nigeria Funds from David and Lucile Packard Foundation

Peplau, L. A., Veniegas, R.C., Taylor, P.L. \& Debro, S.C. (1997). Socio-cultural Perspectives on the Lives of Women and Men. In Freeman, J. (Ed.), Women: A feminist perspective, (4th ed.). Palo Alto, CA: Mayfield Publishing

Roost, M. (2010). Pre-Hospital Barriers to Emergency Obstetric Care- Studies of Maternal Mortality and near-Miss in Bolivia and Guatemala. PhD Thesis, Faculty of Medicine, Acta Universitatis Upsaliensis.

Sychareun, V., Phengsavanh, A., Hansana, V., Sysouvanh. V.S. \& Menorath, S. (2009). Cultural Beliefs and Traditional Rituals About Child Birth Practices in Lao Pdr. The Asian-Pacific Resource \& Research Centre for Women (ARROW). Kuala Lumpur, Malaysia.

Targeted States High Impact Project- TSHIP (2010). "Advancing Health in Bauchi and Sokoto States, Health Facility Rapid Assessment, Baseline Survey Report, Central Project Office, August 2010, Support from USAID

United Nation Population Funds- UNFPA (2004). "Maternal Mortality Updates 2004 Delivery in Good Hands", University of Aberdeen, U.K. 